Artículos 

Publicación semestral. ISSN 1409-2522

Volumen 75 - Número 2

\section{Le tableau vivant: Una forma de trasvase entre pintura y cine. El caso de La ronda de noche (1642) de Rembrandt van Rijn y La ronda de noche (2007) de Peter Greenaway}

Giovanni de J. Orozco Abarca

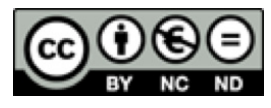

Esta obra está bajo una licencia Creative Commons Reconocimiento-No comercial-Sin Obra Derivada 

Artículos

\title{
Le tableau vivant: Una forma de trasvase entre pintura y cine. El caso de La ronda de noche (1642) de Rembrandt van Rijn y La ronda de noche (2007) de Peter Greenaway
}

\author{
Giovanni de J. Orozco Abarca' \\ Universidad de Costa Rica \\ giovanni.orozcoabarca@ucr.ac.cr
}

Recibido: 12 de diciembre de 2015 Aprobado: 18 de febrero de 2016 .

\section{Resumen}

La presente investigación estudia un punto de encuentro entre el cine y la pintura mediante la representación del tableau vivant en el filme La ronda de noche (Nightwatching, 2007) de Peter Greenaway en relación con el óleo La ronda de noche (Nachwacht, 1642) de Rembrandt van Rijn con el objetivo de visualizar la configuración de una propuesta estética novedosa en el campo cinematográfico a partir del trasvase de una pieza pictórica hacia el cine a través de un proceso de cinematización; en este proceso, el cine adopta otro tipo de arte, en este caso, la pintura. Para abordar esta relación, se toman como referencia dos conceptos que intervienen directamente en la película La ronda de noche y que denotan el carácter pictórico incorporado en el espacio fílmico para hacer efectivo el tableau vivant; uno de ellos es la temporalidad pictórica y el otro término es el de efecto pintado, mediante los cuales, cinematografía y pintura, fundidas en un plano intermedial, logran un trabajo fílmico novedoso e interdisciplinario.

Palabras clave: tableau vivant, trasvase, cine, pintura, cinematización, temporalidad pictórica, efecto pintado.

\section{Abstract}

This research pretends to study the relationship between cinema and painting throughout the tableau vivant in the film Nightwatching (2007) by Peter Greenaway and the painting Night Watch (1642) by Rembrandt van Rijn for visualizing the configuration of a new esthetic proposal in the cinematographic

\footnotetext{
${ }^{1}$ Nota del autor: Se agradece a la Dra. Carolina Sanabria por los valiosos conocimientos transmitidos, los cuales fueron de gran ayuda para la elaboración del artículo.
} 


\section{Artículos}

area with a transfer of a painting to a movie throughout a cinematization process in which cinema adopts other kind of visual art; in this case, it is the painting. To study this relationship, it is necessary to take in account two important concepts, which are in the film Nightwatching, that denote the pictorial character in the movie and they contribute to make possible the tableau vivant; one of this concepts is the pictorial temporality and the other is the painted effect with which cinema and painting, in an intermediate area, make a new and interdisciplinary film work.

Keywords: tableau vivant, transfer, cinema, painting, cinematization, pictorial temporality, painted effect. 
Desde una concepción clasicista del cine, se ha privilegiado la narración más que el aspecto puramente plástico o visual en el texto cinematográfico, a partir de lo cual se ha hablado de un tipo de cine gestado desde una tradición literaria. Al respecto, García-Jambrina y López de Abiada (2002) se refieren a un cine de escritores o guionistas que contribuye y reafirma el prevalecimiento de la noción narrativa del cine en detrimento de la visual. Ante tal panorama, el director cinematográfico Peter Greenaway plantea “[...] como alternativa, un cine «de pintores» y un cine experimental, heredero y continuador de la corriente formalista y estructuralista que existió en Europa durante la década del 60, bajo las etiquetas de free cinema y Nouvelle vogue" (pp. 18-19).

Como un modo de transgresión a ese cine clásico, Greenaway presenta una estética más próxima a la pintura, dejando en evidencia su gusto por el campo plástico-visual, lo cual determina su modo de filmar. El cineasta expone: "[l]a pintura lleva en sí misma un poder de distanciación que me gusta mucho: tiene la capacidad de incluir las características que le son propias (composición color, etc.) y la imagen misma, «el icono», que puede ser contemplado sin identificación emocional [...]" (Greenaway citado por Ortiz y Piqueras, 2003, p. 20). No es de extrañar que en una película como La ronda de noche (2007) se evidencie una notable cinematización del precedente pictórico del célebre óleo homónimo de Rembrandt van Rijn, en referencia a la incorporación de un tipo de arte dentro del espacio cinematográfico, en este caso se trata de la pintura en el cine.

Asimismo, Greenaway ha considerado que la relación entre estas dos artes visuales se gestó mucho antes del nacimiento del cine, pensando en el pintor Johannes Vermeer como el primer cineasta de la historia

[...] por la peculiar forma de trabajar la luz, por su insuperable capacidad para captar el instante. [...] Pero qué hay más misterioso que la luz de un cuadro de Vermeer. Esa fracción de segundo aislada [...] que Vermeer representa [...]. Evidentemente, estas son las principales características del cine. (Greenaway citado por Ortiz y Piqueras, 2003, p. 21)

Este comentario hace alusión a un posible origen de la relación espacio-temporal entre el cine y la pintura desde la perspectiva del director cinematográfico, para quien "[...] el movimiento fílmico está retenido, suspendido por la temporalidad pictórica, de manera que sus imágenes funcionan en noción de continuidad, a modo de collages. Para ello insiste en la composición de la imagen como si de un cuadro se tratara" (Ortiz y Piqueras, 2003, pp. 17 -18). Dicha composición de la imagen como cuadro se puede corroborar en la película debido a la constante presencia de largos planos fijos reforzados con la utilización de miras ópticas, ventanas, arcos, puertas e incluso la cama con dosel del mismo Rembrandt, elementos que encuadran continuamente la imagen filmada. De igual forma, Greenaway, a lo largo de la película, utiliza travellings laterales que simulan 


\section{Artículos}

el recorrido horizontal de un cuadro pictórico a través del movimiento de cámara paralelo a la acción. Por ende, se está ante un proceso de traducción, en el cual, según Eco (2009), siempre coexiste un grado de infidelidad con respecto a un núcleo de presunta fidelidad; este grado de fidelidad o infidelidad se encuentra determinado por el trabajo del traductor.

En este caso, Peter Greenaway, como director y guionista, toma la pintura de Rembrandt así como ciertos aspectos biográficos del pintor y los traduce en un texto fílmico a partir de procesos de negociación en el que convergen un texto de partida (cuadro y texto histórico) y un texto de llegada (película), siendo la negociación "[...] un proceso según el cual para obtener una cosa se renuncia a otra, y al final, las partes en juego deberían salir con una sensación de razonable y reciproca satisfacción a la luz del principio áureo de que no es posible tenerlo todo" (Eco, 2009, p.25).

Como en toda traducción en la que interviene un proceso de negociación, Greenaway pretende retratar un periodo de la vida de Rembrandt caracterizado por la llegada a la cúspide del éxito y la posterior ruina, para lo cual, este director se vale del contexto histórico-social en el que se elabora el cuadro y lo toma como argumento de la trama.

Tanto aspectos biográficos de Rembrandt así como el filme coinciden en varios puntos que constituyen parte de la fidelidad a la que se refiere Eco (2009); entre ellos, es posible mencionar el encargo hecho por parte de la compañía de milicia de arcabuceros de Ámsterdam, dirigida por el capitán Frans Banning Cocq, la cual estaba conformada por un grupo de hombres de diversas clases, quienes, en conjunto, pagaron 1600 florines para aparecer en el cuadro del aclamado artista, suma que dependía de la posición que deseaba ocupar cada uno de los retratados. Así lo afirma la historia:

La compañía de Banning Cocq había sido encargada para decorar, junto a otros retratos colectivos similares de compañías burgueses en armas, la sala grande del cuartel de las guardias cívicas, por entonces recién construido. Junto a las milicias mercenarias, pagadas por los gobiernos de las ciudades, las compañías de burgueses habían jugado un papel de importancia en la guerra contra España, o al menos tal era la tradición, como una ocasión de celebrar estas glorias nacionales con la exposición de los retratos en la gran sala. (Belmonte, 1983, p. 49)

Para infortunio de Rembrandt, su obra de arte no resultó del agrado de sus comitentes debido a la distinta realización que el pintor hizo del cuadro de grupo, ya que, para esta obra en particular, no empleó el modelo básico de retrato corporativo que utilizaban los pintores de la época. De acuerdo con Purilia (2008), este nuevo modelo era caracterizado por el uso ordenado del espacio y ubicación de los participantes, los cuales, usualmente, eran retratados en una posición frontal, en un plano medio o de tres cuartos, ubicados de forma equitativa en torno a un elemento 
central, tal y como lo hizo el mismo Rembrandt en otras de sus obras como La lección de anatomía del Dr. Nicolaes Tulp (1632) y Los síndicos de los pañeros (1662).

De forma contraria a estas obras, Rembrandt decidió cambiar la rigidez conceptual del cuadro de grupo y optó por una representación más dinámica, colocando a los personajes como si se trataran de actores que se dispusieran a representar una función teatral, y retratando el momento preciso en el que el capitán Banning Cocq (personaje alto, vestido de negro y ubicado en el centro del cuadro) da la orden de salida al teniente van Reytenburch (personaje vestido de amarillo y ubicado en el centro de la composición) y a los demás arcabuceros, en conmemoración de la llegada a la ciudad de la reina de Francia María de Médici, viuda de Enrique VI y madre de Luis XIII. La molestia de los retratados con respecto al cuadro trajo consigo otras consecuencias:

La renovación del retrato colectivo operada por Rembrandt, su revolución pictórica, no fueron aceptadas: en lugar de su grandiosa escena «histórica» se preferían los retratos de ex combatientes alienados con trajes vistosos y poses de circunstancias. El resultado fue que $L a$ ronda [de noche] se vio apartada de la gran sala de armas de la guardia cívica y en 1715 quedó relegada a una pequeña sala del consejo de guerra de ayuntamiento de Ámsterdam. En esa ocasión, para adaptarla a un nuevo marco se la mutiló con toda tranquilidad. Se han perdido veintiocho centímetros de altura y nada menos que sesenta y cuatro centímetros de anchura. [...] La tradición románica ha señalado el fracaso de La ronda de noche como un hecho determinante para el futuro de Rembrandt y como el inicio de su decadencia económica. (Belmonte, 1983, p.50)

No solamente en el campo laboral Rembrandt se enfrentó a diversos problemas, también en el ámbito personal. Durante este periodo, muere su esposa Saskia Uylenburgh, hecho que lo ligó al cuido de su hijo Titus de pocos meses de nacido. Con la inesperada muerte de su mujer, Rembrandt se involucra sentimentalmente con una de sus criadas, Geertje Dircx, la cual ayudó en la educación del niño hasta 1649. Antes que Geertje se marchara, una nueva sirvienta, llamada Hendrickje Stoffels, arribó en la casa de Rembrandt, quien sustituyó a la antigua criada y culminó como la mujer de Rembrandt. Estos eventos histórico-biográficos son retomados por Greenaway en la elaboración del texto fílmico.

A pesar de que dichos acontecimientos se aproximan al núcleo de fidelidad desde una perspectiva histórica, toda traducción implica un alejamiento del núcleo como consecuencia de una variación de sustancia, dentro del ámbito visual, produciendo un fenómeno de transmutación en la medida en que "[...] un determinado sistema semiótico puede decir o menos o más que otro sistema semiótico, pero no se puede decir que ambos son capaces de expresar las mismas cosas" (Eco, 2009, p. 419). Lo anterior, evidencia 


\section{Artículos}

cómo la transmutación de materia añade significados, creando relevantes connotaciones que originariamente no eran tales. Por ejemplo, en el análisis que hace Greenaway del cuadro de Rembrandt se efectúa una clara interpretación por manipulación -como consecuencia de la incorporación dentro de la trama- a partir de un crimen delatado por Rembrandt en su propio cuadro. Por lo tanto, este director cinematográfico hace ver lo no dicho (la denuncia de un asesinato) mediante variaciones de significado que se derivan del óleo original. Vinculado con esto, Dusi (2000), citado en Eco (2009), expone:

[...] una trasmutación si encuentra elementos relevantes de lo no dicho en el texto que quiere adaptar, puede elegir realizarlos en la propia materia, [...] «es decir, todo un potencial de indeterminaciones que permitan que el texto de llegada traduzca las ambigüedades y las aperturas semióticas del texto de partida». (p. 438)

\section{Figura 1}

Rembrandt van Rijn. La ronda de noche (1642), detalle.

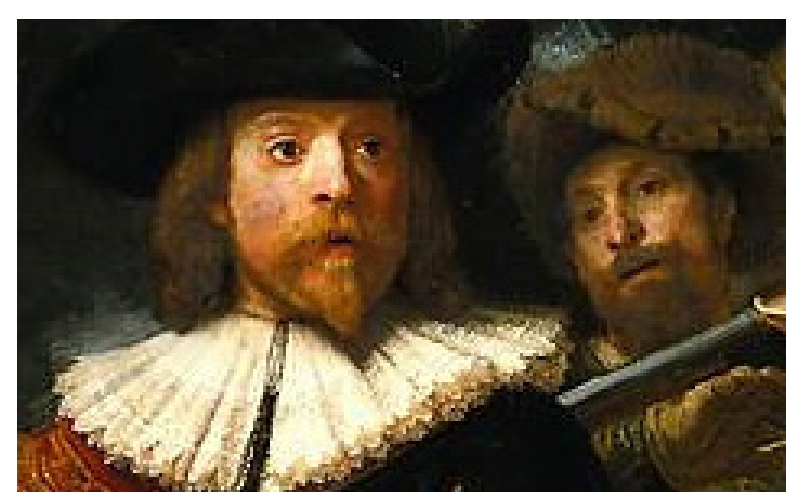

Fuente: ArteHistoria
De este modo, mediante la interpretación por manipulación se añaden elementos dentro del texto pictórico e histórico que, originalmente, no estaban presentes. Como una forma de enriquecer el relato del texto fílmico, Greenaway lleva a cabo variaciones de significado a nivel de los elementos representados en la pintura, planteando la hipótesis de que en el cuadro está plasmada la denuncia consciente de una conspiración de asesinato tras la inesperada muerte del personaje llamado Hasselburg, uno de los retratados del cuadro, el cual muere durante una práctica de tiro con mosquetes.

La osadía de plasmar en el lienzo la denuncia de un crimen, lleva a Rembrandt a incorporar en el cuadro a Horatio - personaje que, en principio, no tenía participación alguna- con un mosquete en su manos como indicio de la culpabilidad del crimen (Fig. 1). Esta acción conduce al pintor a un posterior

\section{Figura 2}

Rembrandt van Rijn. La ronda de noche (1642), detalle.

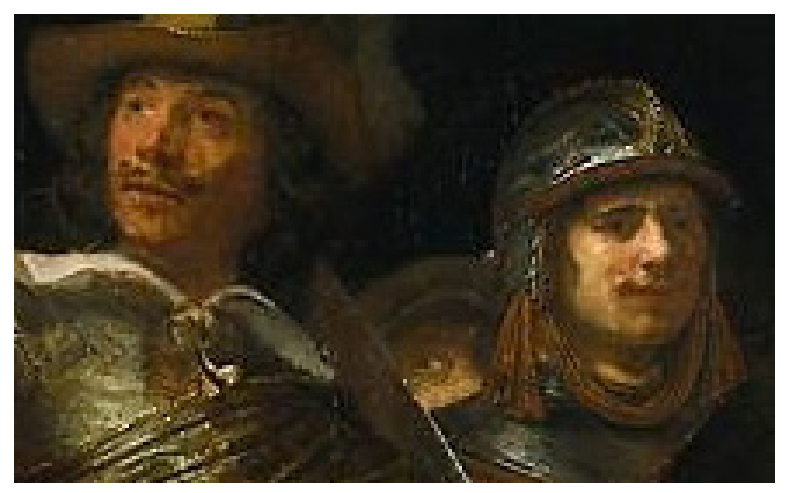

Fuente: ArteHistoria 
declive profesional y personal, tras cosechar varios enemigos dentro del ámbito social de la película, a pesar de que nunca se condena al culpable y la idea del crimen no tiene un seguimiento preciso y resolutorio. Otro elemento sobresaliente que agrega Greenaway es la presencia del mismo Rembrandt dentro del cuadro, de forma específica, el personaje que aparece al fondo de la pintura y del que solo se aprecia un ojo (Fig. 2). El director británico propone así que este ojo pertenece al pintor, el cual se autorretrata como testigo de la escena del crimen. La mirada de este ojo funciona a modo de panóptico que vigila cada una de las acciones de los personajes que se encuentran dentro de la escena pictórica. Según Greenaway, citado por Ferrer (2005):

Rembrandt pintó su propio [Jaccuse] "Yo acuso" a la manera del escritor francés Emile Zola, «contra una compañía de conspiradores capaces de asesinar por razones financieras y políticas». Los denunciados, a su vez, habrían censurado su vida privada desde el momento mismo de la conclusión del cuadro (1642) hasta convertirlo en un marginado. (párr. 4)

No obstante, al manejarse una propuesta estética más cercana a la pintura, no es de asombrarse la añadidura de valores semánticos, tomando en cuenta las evidentes convergencias que puedan existir entre estas dos artes visuales. Al respecto, Subouraud (2010) plantea que el cine es, ante todo, una máquina de reproducir, lo más precisamente posible, no sólo una imagen sino también el movimiento, el cual se posibilita a partir de un espacio que, al igual que en la fotografía y en la pintura, tiene un significado como representación, al traducirse en emociones y sentimientos suscitados en el espectador.

Aunado a esto, en una entrevista dada para el programa español Días de cine (2011), Greenaway manifestó que su película es una explicación de lo que pudo haber pasado cuando Rembrandt realizó su famoso óleo $y$, por tanto, es una lectura propia del texto histórico-biográfico desde una perspectiva distinta a lo que plantea la Historia del Arte. Con este filme, se trata de retomar el concepto pintura de apropiación que el mismo Greenaway expone en la Revista N (2011), en auge en los años ochenta, el cual consistía en tomar una obra de arte y trabajarla de manera continua hasta lograr un acabado único mediante la construcción de imágenes sobre imágenes, logrando, de esta forma, una práctica honorable y legítima, lo cual resulta afín a la interpretación por manipulación, desde el presupuesto artístico de partir de una obra ya existente para crear un trabajo original que difiere, en pequeña o gran medida, del precedente.

Por una parte, la clave para lograr un tipo de cine novedoso, según este director, se encuentra en la interactividad y el aprovechamiento de las nuevas tecnologías en oposición al cine actual, el cual ha agotado todos sus tropos y paradigmas; en él ya se ha visto todo, lo que provoca que el espectador, al observar los primeros cinco minutos de una película, sea capaz de saber qué va a suceder dentro de la 


\section{Artículos}

trama, como consecuencia del predominio de sistemas narrativos banales y repetitivos a lo largo de la historia del cine.

Como esta, son numerosas las opiniones que se han dado respecto a la estética fílmica del director británico. Una de ellas es recogida por Keska (2009) al exponer que Greenaway rechaza el realismo en el cine, esta resistencia "[...] se manifiesta mediante la estilización de la imagen, uso de citas pictóricas, estilización, tableaux vivants" (Keska, 2009, pp. 58-59). Lo cual se valida con la elaboración de filmes como el que se encuentra en análisis. Asimismo, en palabras de Greenaway

[...] el cine «encierra un gran potencial que no se ha utilizado». A juicio del director, el resultado de la falta de exploración del medio ha tenido como consecuencia que se haya convertido «en algo fijo, fosilizado». El [célebre] director reconoció que la innovación suele implicar el rechazo del público, pero aseguró que ésta es irrenunciable. «Cada vez que una nueva película mía sale a la calle noto que se me cae un trozo de público, pero crear significa explorar continuamente». Sin embargo, aclaró que este pesimismo hacia el medio no es endémico: «Soy optimista con vistas al futuro, creo que podremos liberamos de la tiranía del texto, del actor, de las tomas [...]». (Ginart, 1996, párrs. 1- 2)

Por otra parte, dentro de esa línea de innovación a la que apunta Greenaway, existen elementos que intervienen directamente en la película y denotan el carácter pictórico incorporado en el espacio fílmico, los cuales configuran el texto cinematográfico como una obra plástica en sí misma por su conformación estética, logrando así el tableau vivant como una forma de trasvase entre medios heterogéneos, en la que la pintura -materialmente distinta pero de naturaleza visual- es llevada al cine -medio también visual- donde difieren en aspectos como temporalidad y espacio, asociado este último al movimiento. Este concepto de trasvase es explicitado de forma clara por Sánchez-Noriega (2000):

Es evidente que no todo trasvase tiene la misma entidad, al menos en tanto que la diferencia radical entre los medios expresivos exige hacer una obra original [...]. Por ello habrá que distinguir los trasvases en general -que no pueden sino dar lugar a una obra nueva- de las adaptaciones, que, en principio, necesariamente son subsidiarios de la obra original. (p.24)

De este modo, el tableau vivant, como un modo de trasvase entre cine y pintura, se puede definir como la representación de una pintura (Fig. 3) mediante seres vivientes (Fig. 4). Dicho espectáculo adquirió un auge mayor a partir del año 1830:

[e]n los salones burgueses [y] a finales del siglo XIX pasó a formar parte de los espectáculos populares de variedades [...] De hecho, fue uno de los principales espectáculos ante los que se puso una cámara de cine, paradoja sorprendente si se tiene en cuenta que la esencia y la función del tableau vivant es detener el tiempo y el movimiento, justo lo contrario que el cine. (Ortiz y Piqueras, 2003, p. 182) 
Artículos

Figura 3

Rembrandt van Rijn. La ronda de noche (1642).

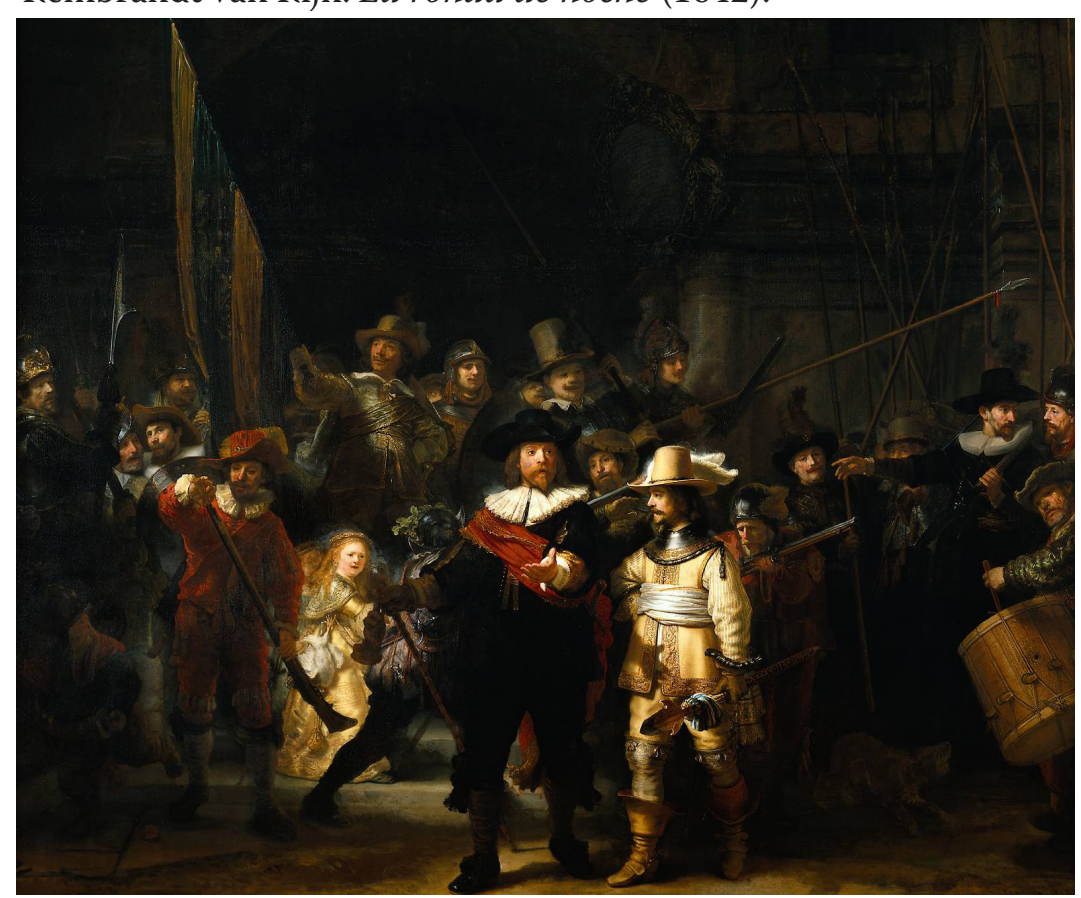

Fuente: ArteHistoria

Figura 4

Plano general. Peter Greenaway, (2007).

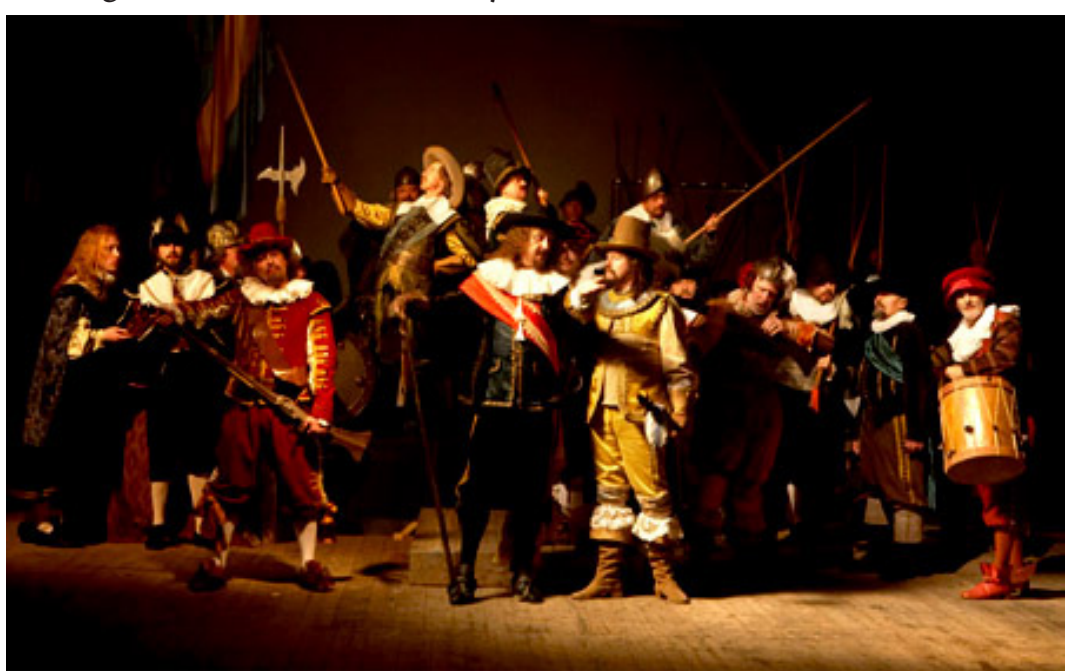

Fuente: Peter Greenaway, (2007). 


\section{Artículos}

Uno de los principales elementos que contribuye a la configuración del tableau vivant es la temporalidad pictórica. Ortiz y Piqueras (2003) plantean que el tiempo, en una imagen fílmica o pictórica, siempre está dado por el movimiento que le otorga el espectador del cuadro a través del movimiento de la mirada, o bien, por el movimiento de cámara en una película. Este punto de vista anamórfico -referente al desplazamiento de la miradadesempeña un papel fundamental, debido a que este desplazamiento -que el espectador de una pintura es capaz de hacer- en el cine es incapaz de concretarse y se le delega a la cámara. "La cámara es un ojo móvil y esta movilidad funciona a veces como factor de verdad, de desmentido" (p. 28).

Precisamente, una de las principales características del tableau vivant es esta caracterización temporal contradictoria, ya que la visualización de un cuadro apela en el espectador la detención del flujo temporal y narrativo para centrarse en un único hecho representado; esta concepción se rompe cuando una pintura es representada ante una cámara en movimiento $\mathrm{y}$, por tanto, se desprende una relación de transferencia en la que el cine dota de movimiento a la pintura, al mismo tiempo que la pintura puede detener el flujo temporal del cine, privilegiando el carácter fijo sobre el móvil de la imagen cinematográfica, al menos en un instante de la película. En el caso de la película en análisis, el tableau vivant del óleo resulta casi natural, puesto que Greenaway se basa en un periodo específico de la vida de Rembrandt, un pintor real dentro del mundo del arte. De tal forma, el tableau vivant está justificado por el mismo relato del texto fílmico y no provoca en el espectador una interrupción temporal y abrupta de movimiento; tal efecto es parte necesaria de la acción filmada.

En esa misma línea de temporalidad en la pintura, en 1766 Gotthold Ephraim-Lessing acuñó el término "momento esencial", que consistía en el detenimiento de la acción representada en un cuadro. De acuerdo con ello, el "momento esencial" del cuadro $L a$ ronda de noche (1642) resulta ser la salida de la compañía de tiradores de Ámsterdam por la puerta de la ciudad para saludar a la reina María de Médici, ya que es este evento el que se plasma en el cuadro de Rembrandt. Sin embargo, "[...] este concepto es válido hasta el impresionismo, cuando la idea del momento esencial se sustituye por la del instante fugitivo, que en realidad es una variación de ese momento esencial, sin connotaciones narrativas; un intento de conseguir la instantánea absoluta" (Ortiz y Piqueras, 2003, p.31). Ese "momento esencial" -o su variación denominado "instante fugitivo" más próximo a la fotografía - en el cine resulta problemático, pues el acontecimiento representado se da por el encadenamiento sucesivo de imágenes cualesquiera, por lo que el "momento esencial", en el filme, se presenta a través de la temporalidad que implica el movimiento continuado de imágenes.

El otro elemento que configura la estética predominantemente plástica en la película, y consecuentemente el tableau vivant, es el 


\section{Figura 5}

Plano abierto. Peter Greenaway, 0:06:21, 2007.

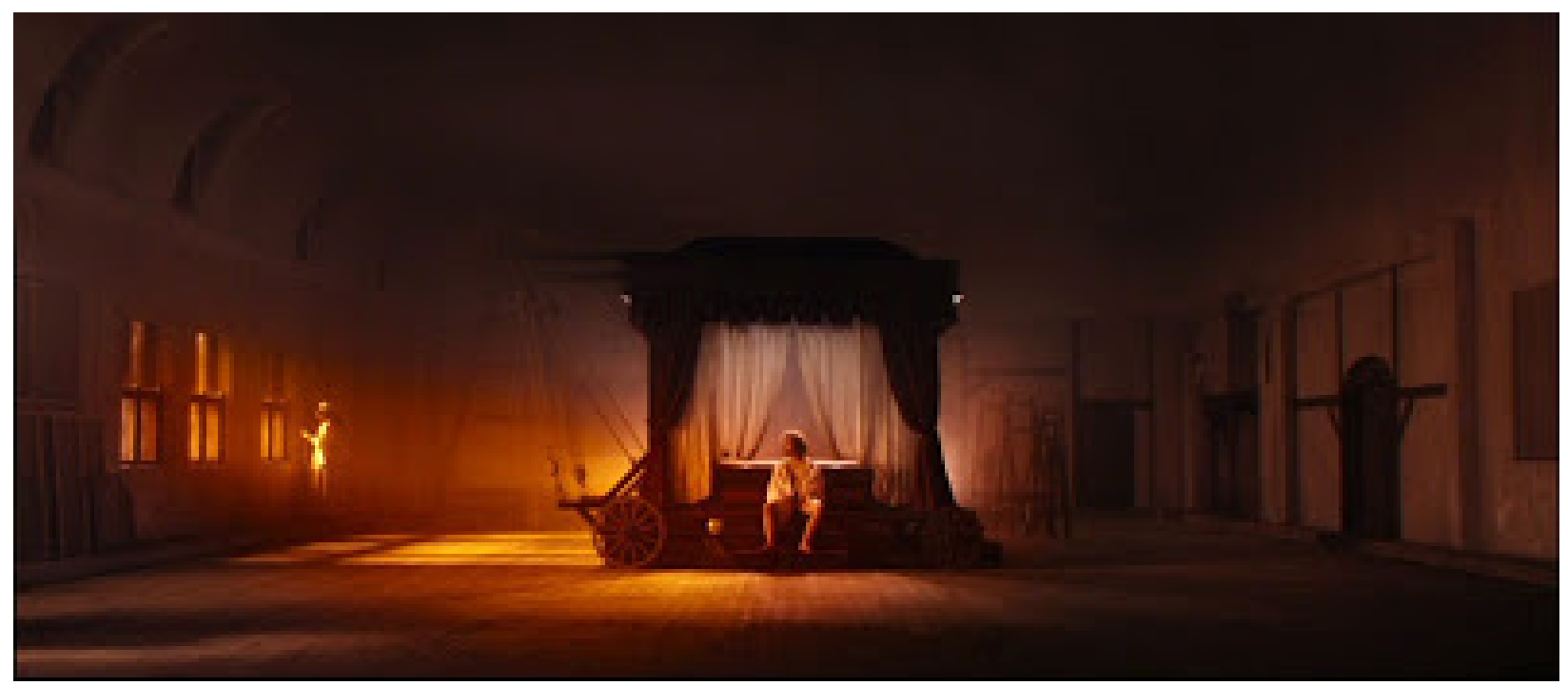

Fuente: Peter Greenaway, 2007

denominado efecto pintado (effecto di-pinto), el cual se materializa desde el instante en que el espectador visualiza el cuadro. Costa (1991) establece que este efecto interfiere en la lectura del encuadre en la pantalla, debido al cruce de dos efectos de realidad distintos: la realidad de la película, el contexto holandés de mediados del siglo XVII en el que se mueve Rembrandt y la alusión a una escenografía con matices pictóricos por donde se mueven los actores, como si se tratara de una pintura viviente; sin embargo, la interferencia de la lectura del encuadre va a depender de la habilidad del director cinematográfico a la hora de construirlo. Además, Costa (1991) plantea que ese efecto pintado se manifiesta en dos modos: como efecto pictórico (pitturato) y como efecto cuadro.
En la primera acepción como efecto pictórico, significa un verdadero efecto espacial, puesto que se trata de crear determinados efectos escenográficos. Es un medio al servicio de la representación cinematográfica [...] En su segunda acepción, el efecto cuadro, «la instancia metalingüística se traduce en una confrontación entre dos modelos, dos modos de estructurar las coordenadas espacio-temporales y los valores luminosos y cromáticos. En otros términos, el efecto cuadro produce un efecto, más o menos evidente, de tiempo suspendido, de espacio definido (o cerrado) y de selección cromática, mientras que el plano cinematográfico se 


\section{Artículos}

caracteriza por ser una especie de calco icónico de la duración, de la movilidad del espacio y de la variabilidad cromática». (Costa, 1991, pp.155-157)

En el caso del presente texto cinematográfico, el efecto pintado se da en modo de efecto cuadro, debido a la difuminación cromática y de luz en numerosas escenas; por ejemplo, el plano abierto al inicio del texto fílmico en el que Rembrandt conversa con su esposa Saskia sobre la naturaleza de los colores-, en cuanto se menciona un color especifico, el fondo escenográfico se torna de tal matiz (Fig. 5). Lo anterior, crea en el espectador la sensación de tiempo suspendido, como si, en efecto, se tratara de una pintura en la que los personajes realizan pequeños movimientos corporales, acompañados de una inadvertida gesticulación que confunden al espectador, quien escucha las voces de los personajes mientras se aprecia un cuadro estático el cual instaura la sensación de una voz en off ante un cuadro pictórico. Asimismo, el efecto pintado en sus dos modos de realización desempeña una importante función:

El efecto pintado, sea en el sentido de efecto pictórico o en el de efecto cuadro, tiene una función, más o menos intencional, de perturbar la total afirmación del universo diegético, de la historia, en cuanto la desmiente al menos parcialmente, con la imperfecta realización de la ilusión de la realidad (efecto pictórico), o la excede con un plus de presencia de la dimensión subjetiva del autor o de la caracterización figurativa extraña al régimen realista instaurado en la película (efecto cuadro). (Costa, 1991, p.159)

Otra característica que interviene en el efecto pintado es la técnica pictórica del claroscuro, basada en la plasmación de formas a través de luces y sombras en una composición armoniosa de contrastes de luces y oscuridades; además, esto resulta ser un rasgo sumamente representativo del estilo de Rembrandt. "La luz, y la correspondiente sombra, surgió como cualidad óptica ya en la pintura naturalista del siglo XV, en el sentido de rechazar el tratamiento de las puras formas plásticas en favor del contraste tonal o claroscuro" (Boeck, 1970, p. 53). El carácter del claroscuro adquiere un mayor auge en el barroco y se manifiesta como un rasgo marcado en todas sus pinturas; de igual forma, dota a la representación de cierto grado de verosimilitud. Como cualidad óptica, el claroscuro remarca las funciones de la luz en la imagen, a saber dramática y atmosférica.

La idea de interrelación entre cine y pintura a modo de tableau vivant se refuerza con la propuesta que hace Aumont (1997) sobre las diversas funciones que el cine ejerce a la hora de reproducir cuadros pictóricos. De esta manera, resulta pertinente aclarar el modo de aparición del cuadro pictórico dentro de la película.

Para ello, Ortiz y Piqueras (2003) mencionan que tal inserción puede darse como objeto en sí mismo o formando parte del atrezzo, tal y como se hace en la película en el momento en que Rembrandt recorre una galería 
de cuadros de grupo y se puede apreciar $L a$ Guardia Cívica de Ámsterdam celebra la Paz de Münster (1648) de Bartholomeus van der Helst, en cuyo caso asume una clara función de reencuadre, o bien, representado por los actores en el encuadre, como tableau vivant, lo anterior revela siempre una autorreflexión en torno a la representación visual.

Según Aumont (1997), la presencia de una pintura en la imagen filmada cumple diversas funciones, como una operación de diegetización, en la que cuadro es planteado como un mundo ficcional. En este caso, es el mundo recreado en La ronda de noche (1642) que forma parte del argumento de la película misma, de modo tal que la obra de Rembrandt es una escena unitaria y, a la vez, susceptible de descomposición dentro del texto fílmico; una operación de narración por la secuenciación de estos -fragmentos de cuadro-fragmentos de escena que se pueden apreciar en el opening de la película y, finalmente, una operación de psicologización, la cual es consecuencia de las dos operaciones precedentes. Aumont plantea que cada cuadro remite a la conciencia del pintor, pues es quien le da origen a ese mundo ficcional plasmado en el lienzo. De esta forma, la conciencia de Rembrandt en el cuadro se debate entre la representación de un grupo de arcabuceros y la denuncia de un crimen, disyuntiva que lo lleva a optar por autoretratarse, según la propuesta de Greenaway.

Además, Aumont (1997) refuerza la idea de las diversas funciones de la pintura en el cine al proponer una tipología funcional de la luz en la imagen, lo cual se adecúa a la composición barroca de La ronda de noche (2007). Para la propuesta artística que ofrece Rembrandt y posteriormente Greenaway, es posible plantear una función dramática de la luz,

[...] vinculada a la organización del espacio como escénico. Los medios de acción de la luz son aquí casi innumerables y no hay razón para no inventar constantemente otros nuevos. Bañando el conjunto de la escena, puede indicar su profundidad, subrayar e incluso definir el escalonamiento de las figuras $[\ldots]$ Puede hacerse aún más activa -como en todos los pintores del claroscuro-, si se une al gesto para alcanzar la elocuencia retórica perfecta [...] o designar, indexar, las zonas sensibles del cuadro corno en La ronda nocturna. Aquí, [...] la representación de las fuentes luminosas adquiere una importancia nueva vinculada a un trabajo de «verosimilización». (p. 132)

Mediante este tipo de función, tanto el cuadro cinematográfico como el pictórico pueden valerse de la función dramática de la luz para realzar u ocultar elementos que intervienen en la escena, así como valerse de los cambios de luz propios del claroscuro y dotar de verosimilitud al cuadro representado. Ambas, imagen pictórica e imagen fílmica, también emprenden una función atmosférica a través de la incorporación de la luz, cuyo origen data, precisamente, de que "[...] la mayor parte de los Rembrandt confían lo esencial de su efecto a una utilización calculada de la iluminación para delimitar 


\section{Artículos}

regiones diversamente significantes en la imagen [...] para bañar a la vez el cuadro [...] con una luz cuya «connotación» impondrá la apreciación del conjunto sobre el cuadro" (Aumont, 1997, p.133).

Esta función resulta relevante a partir de la tesis que maneja Aumont (1997), puesto que el efecto atmosférico ha sido el más utilizado por los medios audiovisuales de comunicación masiva (cine, televisión y publicidad):

[...] No obstante, fue también a través de este efecto como pasó indiscutiblemente, uno de los más conscientes préstamos que el cine recibe de la pintura. Los cineastas, y mucho más los operadores de toma de vistas, reflexionaron y disertaron largamente -desde los años veinte- sobre la amplitud y la fuerza de los medios expresivos proporcionados por la luz difusa. [...] La iluminación «a lo Rembrandt» era una expresión comprendida por todos los cineastas alemanes o rusos entre 1920 y 1935. (p. 134)

De esta manera, Aumont (1997) concluye que la paleta es el mejor atributo del pintor y su instrumento por excelencia. El cine tropieza en su pretensión de producir un instrumento sólo comparable y, así también en él, el color parece siempre imitado, por lo que -paradójicamente- hace pensar en la pintura, como si no pudiese venirle de ninguna otra parte. Siguiendo con lo anterior, es posible deducir que cine y pintura utilizan la luz y color como instrumentos de construcción de la imagen, para dotarla de realismo mediante la manipulación de texturas y formas, suscitar emociones en el espectador y conformar una obra de arte visual que trascienda más allá de ser un mero elemento icónico.

En este sentido, Del Real (2007) expone que "[...] el cine es fundamentalmente luz reconvertida en espacio y tiempo capaces de engendrar o acoger un drama que es donde entra la palabra y su habilidad para apropiarse del conjunto"(p.70). Es decir, la luz en la imagen fílmica no solamente es un artificio de luminosidad que forma parte de la escenografía del lugar de grabación, sino que además se apropia y determina la línea argumental del texto e interviene como un elemento modelador de la acción y los personajes.

En conclusión, con esta investigación, se ha pretendido establecer un puente relacional entre cine y pintura a través de una forma de trasvase como es el tableau vivant, considerando que las posibles conexiones entre ambos tipos de arte no determina la dependencia o independencia entre ellos; por el contrario, ambos se funden en un medio único forjado dentro de un campo interdisciplinario, cuyo mayor beneficiario es el espectador al encontrarse ante una fusión de géneros artísticos.

La confluencia de artes que se concentra en la película genera que el texto fílmico vaya más allá de la representación audiovisual, lo cual la enriquece enormemente y le da un matiz de obra de arte completa por su carácter ecléctico, al contener elementos pictóricos, históricos, dramáticos y cinematográficos; todos ellos interrelacionados y complementados en un mismo espacio. 
Además, con esta propuesta, Greenaway saca el mayor provecho posible al elemento icónico mediante la utilización de constantes encuadres a través de miras ópticas que dan la sensación de un recorrido museístico mediante la secuencia de planos. En cada uno de esos planos que simulan pinturas, se evidencia una puesta en escena de artificiosa teatralidad y barroquización al mejor estilo de la pintura de Rembrandt.

Por lo tanto, con esta obra cinematográfica, Greenaway toma partida de su conocida faceta como pintor y aprovecha la estética pictórica de Rembrandt para lograr un trabajo único que rompe los límites de convergencia artística, produciendo un deleite visual, objetivo nada fácil si se toman en cuenta los desafíos que implica una traducción sujeta a la trasposición entre sistemas semióticos que varían en su naturaleza visual pero que pueden coexistir dentro de un plano intermedial, en el que se sincronizan tiempo, espacio, luz y color en un único texto pictórico-fílmico en función de un tipo de cine novedoso.

\section{Referencias}

ArteHistoria. (s.f.). La ronda de nohce. Recuperado de http://www.artehistoria.com/ v2/obras/57.htm

Aumont, J. (1997). El ojo interminable. Cine y pintura. Barcelona: Paidós.

Belmonte, I. (1983). Rembrandt. Madrid: Debate.

Boeck, W. (1970). Rembrandt. Barcelona:
Editorial Labor S.A.

Costa, A. (1991). Cinema e pittura. Turín: Loescher.

Del Real, A. (2007). Ut pictura kynesis: Relaciones entre pintura y cine. (Disertación doctoral). Recuperado de http://biblioteca.ucm.es/tesis/ghilucm-t29714.pdf

Eco, U. (2009). Decir casi lo mismo. La traducción como experiencia. Barcelona: Debolsillo.

Etnilumidad Films. (2011). La ronda de noche. Entrevista para Días de cine [video]. Recuperado de https://www.youtube. com/watch?v=U0ILv2oxIGs

Ferrer, I. (2006). El crimen de La ronda de noche. El País. Recuperado de http:// elpais.com/diario/2006/06/07/cultura/1149631208_850215.html

García-Jambrína, L. y López de Abiada, J.M. (2002). Cine literario y literatura Cinematográfica, Hispanorama, 95: 9-15.

Ginart, B. (1996). Peter Greenaway: El cine se ha convertido en un fósil. El País. Recuperado de http://elpais.com/diario/1996/11/06/cultura/847234805_850215.html

Kasander, K. (Productor) y Greenway, P. (Director). (2007). La ronda de noche (Nightwatching) [película]. Canadá-ReinoUnido-Polonia-Holanda: Manga Films Recuperado de http:// www.miracine.net/2008/10/la-rondade-noche.htm 


\section{Artículos}

Keska, M. (2009). Peter Greenway: Un ilustrado de la Era Neobarroca. Interacciones entre cine y corrientes artísticas. Granada: Editorial de la Universidad de Granada.

Ortiz, A. y Piqueras, M. (2003). La pintura en el cine. Cuestiones de representación visual. Barcelona: Paidós.

Purilia. (2008). La Ronda de Noche. Revista de Cine Encadenados. Recuperado de http://www.encadenados.org/rdc/ sin-perdon/729-la-ronda-de-noche4

Revista Ñ. (2011). Peter Greenaway: El cine es un medio del pasado. [video].
Recuperado de https://www.youtube. com/watch?v=Y03xcI1igac

Sánchez Noriega, J. L. (2001). Las adaptaciones literarias al cine: un debate permanente. Comunicar, Revista de Comunicación y Educación, 17: 65-69.

Subouraud, F. (2010). La adaptación: El cine necesita historias. Barcelona: Paidós.

Van Rijn, R. (1642). La ronda de noche (Nachwacht). Óleo sobre lienzo. Ámsterdam: Rijksmuseum. 